\title{
Action Research: a Supplementary Source for the English Langauge Teachers
}

\author{
Poornima Varalakshmi. K, Shanmugathai M
}

\begin{abstract}
This paper tries to explore that, Action Research is a supplementary source for English Language Teachers to bring out better teaching outcome of the teachers and better learning outcomes of the students. In the current scenario, apart from the syllabus, English Language teachers expect a supplementary source to follow a new strategy in order to satisfy the expectations of the students inside the classroom. They face many challenges in the classroom and one of the important problems is to draw continuous involvement of the students as well as to create good understanding of the subject in the classroom. In this connection, Action Research helps the teachers to explore effective teaching strategy in the classroom. This Action Research is integrated with a new approach called MUSE (Manageable, Urgent, Significant and Engaging), that helps the teachers to plan effectively. Besides, it is an exploratory or activity based classroom research and so it encourages the students to learn effectively and understand clearly with more involvement in the classroom. This study suggests a need for the supplementary source and it also focuses on Action Research to aid the teachers.
\end{abstract}

Keywords: Supplementary, Action Research, Manageable, Engage, Integrate, Exploratory

\section{INTRODUCTION}

Nowadays, English Language Teachers play a predominant role to sharpen the skills of the students. The English Teacher plays a vital role in improving the proficiency in the students at higher level of education [4]. But, teachers face many challenges in the field of teaching. In particular, ELT teachers undergo lots of problems in connecting the students with their thoughts inside the classroom. One of the main reasons is the gap between the teachers and students expectations. So, it's a crucial time for the teachers to find a solution for their problems. The teacher is expected to meet the needs of the learners This can be done by adopting learning-centered, project-based and activity-oriented approach in the classroom [4]. In other words, the students also expect many activities based and technology based teaching in the classroom. Hence, there is a gap in between the teacher and students in the classroom itself. In order to fill this gap, Action Research acts as a supplementary source to create a network or link between the teachers and students with a view to enhance the teachinglearning process .

Action research is gaining grounds in the educational arena around the world [5]. Action Research or classroom -based research is steadily gaining popularity in the Indian context

Revised Version Manuscript Received on 10 September, 2019.

Poornima Varalakshmi. K, Department of English, Sri Sai Ram Institute of Technology, Chennai, Tamilnadu, India. (Email: poornima.eng@sairamit.edu.in)

Shanmugathai M, Department of English, Sri Sai Ram Engineering shanmugathai.eng@sairam.edu.in) College, Chennai, Tamilnadu, India (Email:

because it focuses on the teacher's real-life classroom issues and solving those through an enquiry-based approach [1]. So, it is the right time for the teachers to revive their teaching methodology with the support of Action Research, to meet the recent demands of the students. Fig 1 shows the entry points of Action Research.

Entry Points for Action Research

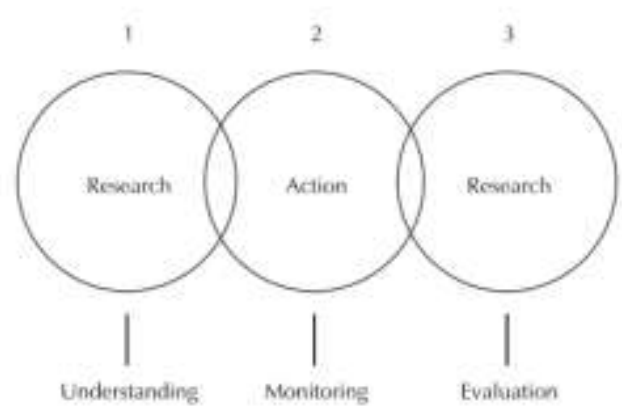

Fig 1 Entry Points for Action Research [7]

Continuous Professional Development is very essential for all the teachers to enhance the teaching pedagogy inside the classroom. Besides, many teaching strategies are emerged in the field of teaching to guide the teachers. Action Research is one of the best strategies that facilitate the teachers with creative ideas in order to help the students to face the challenging world confidently. Classroom is a place of interaction and collaboration between learners and the teacher [6]. It is important to develop a package of teaching-learning materials for classroom use in order to engage children in active learning [2]. Students are always passive inside the classroom and so they fail to show interest in the English Subject. A teacher has to use a variety of teaching-learning materials in the classroom, especially to teach a second language like English, as it is challenging for $\mathrm{him} /$ her to sustain learner motivation for one full academic year using a single textbook [2]. In this connection, Action Research acts as an added source to the teachers to bring out a better teaching-learning outcome. Meyer (2000) comments that action research's strength lies in its focus on generating solutions to practical problems and its ability to empower practitioners, by getting them to engage with research and the subsequent development or implementation activities [1]. The purpose of all research is to generate new knowledge. Action research generates a special kind of knowledge [13]. This is done through reflective cycles in the process of Action Research. 
WHERE DID ACTION RESEARCH CONE FROM? IT
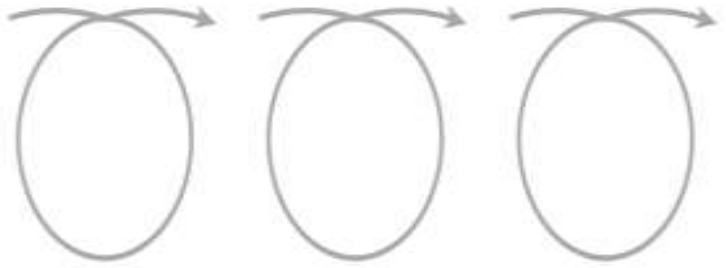

AGURE 4.1 A cycle of action-reflection cycles

Fig 2 A cycle of action-reflection [13].

It emphasis on new strategies and also encourages collaborative or peer relationship, reflective thinking, problem-solving, teaching learning process, career enhancement, use of technology etc., It fulfills the needs of the fast growing world. Action research enables practitioners to ressess learning-teaching difficulties and other issues of classroom transaction strategies and solve immediate problems in learner development.....[3].

\section{AN OVERVIEW OF THE PAPER \& RESULTS}

The central idea of the action part of AR is to intervene in a deliberate way in the problematic situation in order to bring about changes and, even better, improve-ments in practice [9]. Also, it is an exploratory research and so it encourages reflective thinking. The teachers are able to analyze the problems critically through observation and data collection. Action Research proves an effective strategy as observation, data collection and analysis remains a part of own practices for specific purpose in solving problems related to teaching and learning difficulties [3]. It makes the teachers to raise reflection questions within themselves to find out the solution to the problems.

At first it guides the ELT teachers to identify the problems they face in the classroom through clear analysis. Next, it makes them to focus on one particular or major problem they face in the classroom. Since, it acts as a remedy to the problems faced by the teachers inside the class; it motives the teachers through various questions within themselves. Fig 3 shows the Action Research Designs and Questions [8].

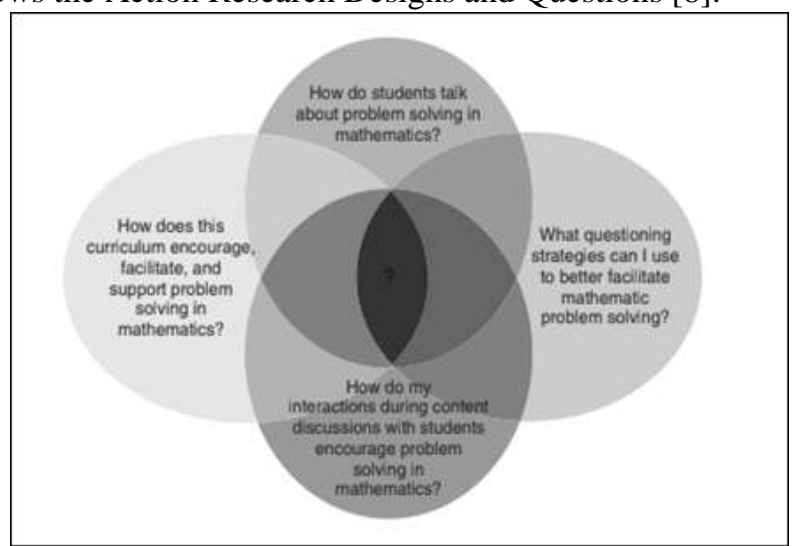

Fig. 3: Action Research Designs and Questions [8].

As the problems are identifies, it guides the teachers to take necessary action through reflective thinking process. So, it enables the teachers to apply PLAN, ACT OBSERVE
AND EVALUATE technique. Fig 4 shows the components in teacher research [12].

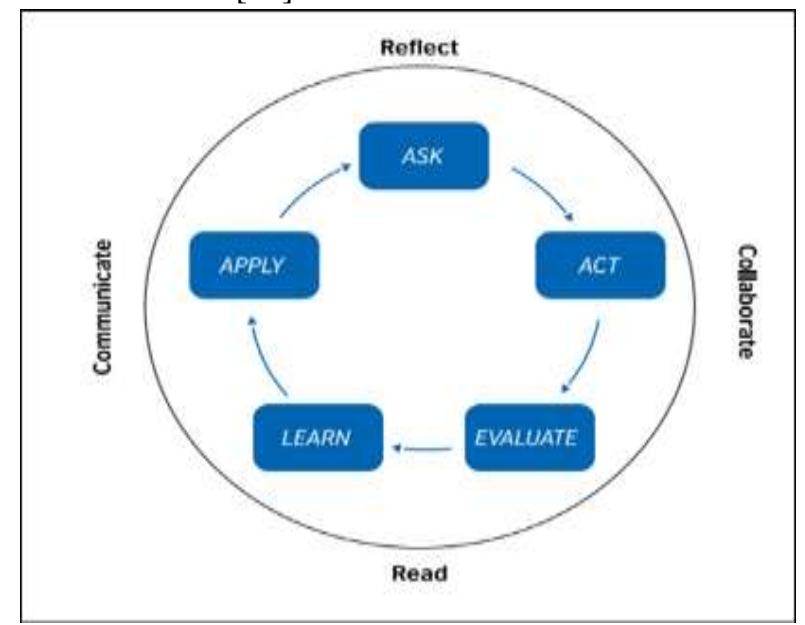

Fig 4 Components in teacher research [12]

Later, it also helps the teachers to collect data as a source of feedback through qualitative or quantitative approach from the students. Through this, peer relationship of the students is also improved in the class. Apart from this, AR also creates a collaborative environment for the teachers and it also makes professionally exhilarating teachers in the society [10]. It also explores the use of technology inside the classroom and so it forms a platform for both the teachers and students in the field of teaching learning process. AR is a reflective process that aims to solve a particular teaching-learning problem that has been identified [9]. Fig 5 shows the Professional Development through Action Research [11].

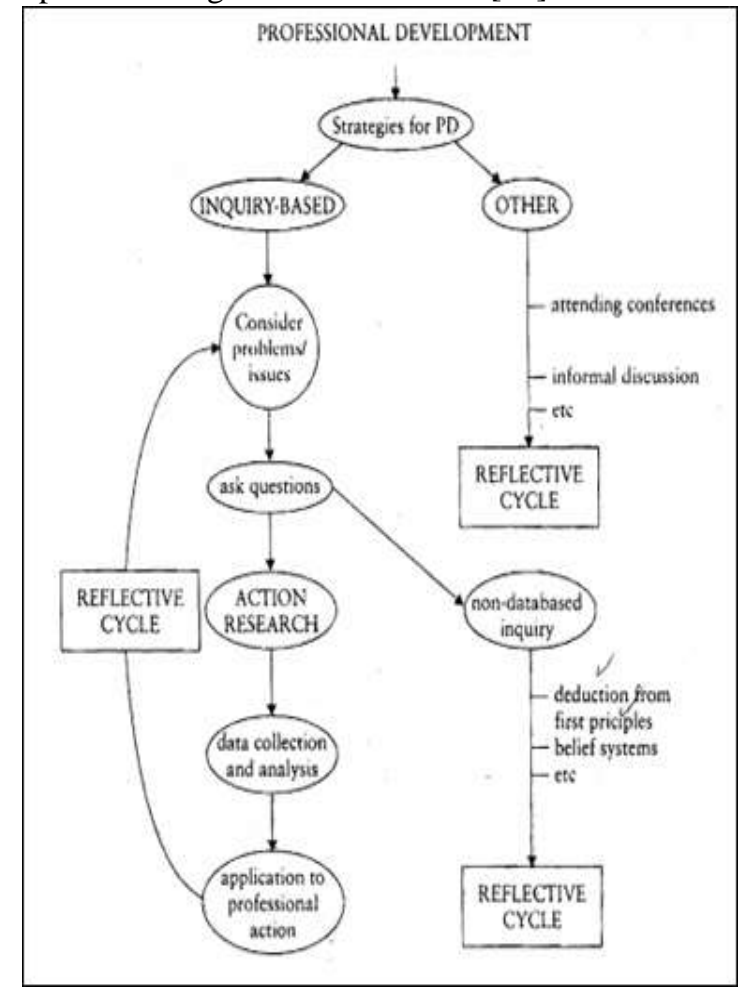

Fig.5 Development Steps [11] 
Since it is a cyclic process, the teacher continues the cycle of actions, until he or she accomplishes a solution to the identified problem. Fig 3 shows the cyclical process of Action Research.

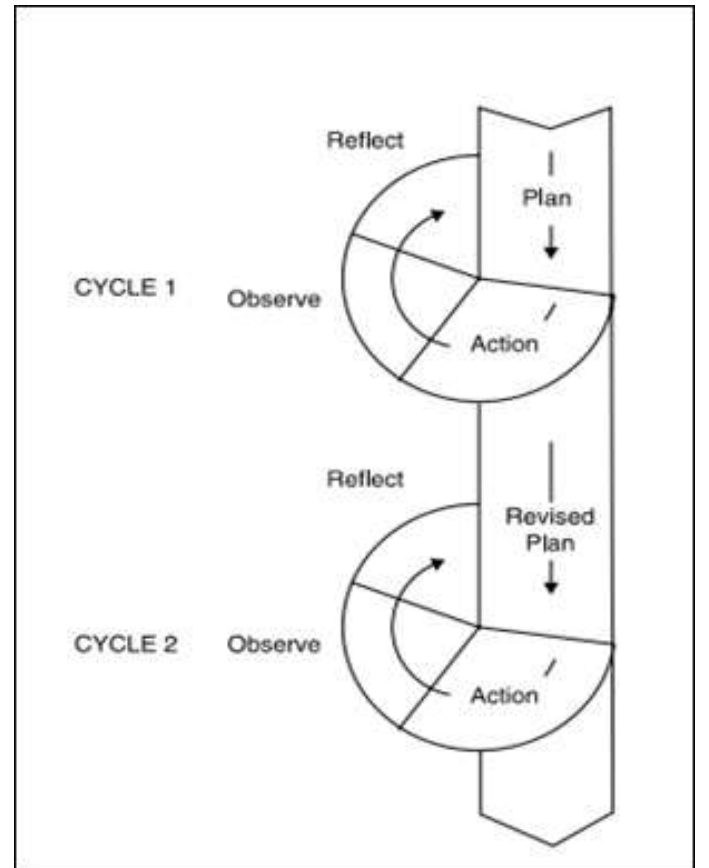

\section{Fig.6 Cyclical AR model based on Kemmis and McTaggart (1988) [9].}

\section{CONCLUSION}

Action Research is the best supplementary source for the teachers because it motivates the learners and helps the teachers to teach effectively. Also, it improves the classroom dynamics and encourages the learners to develop better learning strategies [10]. AR is a transformative means of responding to the changing profiles of their classes and developing new teaching strategies and approaches to meet the need of heterogeneous students [10]. Thus, AR acts as a supplementary source for the ELT teachers to improve the CPD strategies as well to bring out the solution to the problems. At last, it also fills the gap and acts as a bridge to make connection between the teachers and students. It exposes new techniques for the teachers in order to explore new strategies in the field of teaching. It also facilitates the demanding needs of the students through activity based learning. Hence, it is the best supplementary source for the ELT teachers in all aspects.

\section{REFERENCES}

1. Ipshita H Sasmal, Action Research through Mentorship Model: A sustainable Framework for profession development, Journal of English Language Teaching, Vol 60/5 September - October 2018.

2. Ravinarayan Chakrakodi, 'The Jamaican Fragment': using video to add a new dimension to the lesson, Edited by George Pickering and Professor Paul Gunashekar, Innovation in English Language Teacher Education, pp: 87\& 88, 21-23 February 2014.

3. Hitesh C Bhakat, Action Research: An Effective Strategy for Continuing Professional Development, The Journal of English Language Teaching (India) (A Peer Reviewed Journal), Vol. 59/2, March - April 2017.

4. T. Sridevi, English for Specific Purposes (ESP) in India: Present Status, The Journal of English Language Teaching
(India) (A Peer Reviewed Journal), Vol. 59/1, January February 2017.

5. Madhavi Voleti, Teacher Workshop on Using ICT Tools and Digital Narratives- A Report, Journal of English Language Teaching, Vol. 60/6 November-December 2018.

6. Ritu R. Agarwal \& H.P. Desai, Reinventing the Mode of Teaching: Question as a way of learning, The Journal of English Language Teaching (India) Volume LIX Number 5, September - October, 2017.

7. Richard Sagor, How to conduct Collaborative Action Research, pp :8, 1992.

8. Donna Kalmbah and Kevin Carr, Becoming A Teacher Through Action Research, Process, Context, and Self-Study, III Edition, pp: 57, 2014.

9. Anne Burns, Doing Action Research in English Language Teaching, A Guide for Practitioners, pp: 2\&9, 2010.

10. Anne Burns, Collaborative Action Research for English Language Teachers, pp: 7-39, 215-227, 1999.

11. J. Michael, Wallace, Action Research for Language Teachers, pp: 14, 1998.

12. Simon Borg, Teacher research for professional development, Edited by George Pickering and Professor Paul Gunashekar, Innovation in English Language Teacher Education, pp: 25, 21-23 February 2014.

13. Jean McNiff and Jack Whitehead, All you need to know about Action Research, pp: 12 \& 37, 2006 